Finisterra, XXXVI, 71, 2001, pp. 117-132

\title{
A CIÊNCIA DAS ALTERAÇÕES CLIMÁTICAS
}

\author{
SURAJE DESSAI ${ }^{1}$ \\ RICARDO TRIGO ${ }^{2}$
}

\begin{abstract}
«É por causa da interdisciplinaridade da climatologia que na análise do problema das variações do clima se põem questões de índole tão diversa e de tão difícil solução»

José Pinto Peixoto in «As Variações do Clima e do Ambiente»
\end{abstract}

\section{INTRODUÇÃO}

Neste início de Milénio, a generalidade da comunidade científica está finalmente convencida de que o clima do nosso planeta está a sofrer alterações, não só como resultado da variabilidade natural do sistema climático, mas também induzidas pela actividade humana. É de salientar, no entanto, que subsistem grandes dúvidas relativamente à magnitude da contribuição antropogénica para estas alterações. Para além dum acompanhamento muito rigoroso das alterações climáticas $(\mathrm{AC})$ verificadas num passado recente, a comunidade científica passou a dispor, na última década, de um importante instrumento computacional; os Modelos de Circulação Global (Global Circulation Models GCMs). São estes modelos que nos indicam que o aumento generalizado da temperatura média do planeta ou do nível médio do mar nos últimos 100 anos, podem representar "apenas» o início de um conjunto de alterações bastante mais vasto.

A qualidade das previsões de possíveis climas futuros fornecidas pelos GCM dependem em grande medida dos cenários relativos às emissões dos principais

1 Estudante de Doutoramento em ciências do ambiente na School of Environmental Sciences, University of East Anglia, Norwich, NR4 7TJ, UK e investigador associado na Euronatura, Centro para o Direito Ambiental e Desenvolvimento Sustentado, Observatório Astronómico de Lisboa, Tapada da Ajuda - Edifício Leste, 1349-018 Lisboa e responsável pela Unidade de Suporte Técnico do projecto SIAM (Scenarios, Impacts and Adaptation Measures), e-mail: s.dessai@uea.ac.uk

2 Doutorado em climatologia pelo Climatic Research Unit, University of East Anglia, Norwich, Reino Unido. Professor no Departamento de Engenharia Civil, Universidade Lusófona, Campo Grande 376, 1600 Lisboa e Investigador no grupo de Meteorologia do Departamento de Física, Faculdade de Ciências, Universidade de Lisboa, e-mail: rtrigo@fc.ul.pt 
Gases de Efeito de Estufa (GEE). Estes cenários sofreram uma revisão acentuada nos últimos 8 anos, precisamente desde que foi publicado o relatório suplementar do IPCC em 1992. Deste intenso esforço realizado nos últimos anos, resultaram 4 cenários que a comunidade de modeladores está neste momento a utilizar para simular futuras mudanças na temperatura, bem como relativas a outras variáveis. Os impactos das AC foram igualmente analisados do ponto de vista socioeconómico; por exemplo, de que forma poderão vir a afectar a distribuição de recursos hídricos ou a produção agrícola em diferentes partes do planeta. Em relação a todos estes parâmetros (de interesse imediato para a vida de todos nós) são de salientar a coexistência de impactos negativos e positivos, dependendo essencialmente da localização geográfica. No entanto, e de uma forma geral, os impactos negativos parecem exceder consideravelmente os positivos.

O relatório do IPCC dá grande ênfase a uma estratégia de adaptação com vista a estes potenciais impactos. Contudo, a maior parte dos esforços internacionais tem-se dirigido a medidas e políticas de mitigação e redução de emissões de GEE. Alguns cientistas (PARRY et al., 1998; PIELKE, 1998) começam agora a sugerir que se deve adoptar essencialmente uma estratégia de adaptação às AC. Segundo estes autores, a adopção do Protocolo de Quioto ou mesmo de maiores reduções nas emissões de GEE não irão reduzir os efeitos mais nefastos dos impactos projectados. Tal deve-se, por um lado, ao facto dos países em desenvolvimento não terem qualquer tipo de responsabilidade perante o Pro-tocolo e, por outro, à inércia do próprio sistema climático que provocará sempre as AC (mesmo que haja grandes reduções nas emissões de GEE num futuro próximo). Em suma, não se pode menosprezar estratégias de adaptação se se quiser resolver de forma eficaz este problema.

Esta síntese pretende também frisar a dificuldade de se traduzir o conhecimento científico em acções políticas concretas. Se, à primeira vista, tal tarefa pode parecer relativamente fácil (e em teoria é), na prática tal não se verifica. $\mathrm{O}$ facto de todas as conclusões na área das ciências exactas terem de ser obtidas de forma «estatisticamente significativa com níveis de confiança de pelo menos 95\%» pode criar complicações adicionais na transmissão das principais conclusões para o sector político, aumentando as dificuldades deste em actuar face às incertezas existentes. Este tipo de dificuldades acontece em quase todos os ramos científicos relacionados com o ambiente e as AC não são excepção à regra. Todos os cenários bem como os impactos socioeconómicos aqui focados mostram que o nosso futuro e, mais importante ainda, o das próximas gerações, não parece estar fora do "perigo» da interferência humana no sistema climático. Embora haja incertezas, baseando-nos no "principio da precaução», deveríamos actuar quanto antes para não termos de remediar mais tarde.

Portugal, como membro pleno da União Europeia e da OCDE não pode ser um mero observador passivo de todas estas realidades. Assim, não só deveria haver um incentivo a programas nacionais de investigação das AC com um forte carácter interdisciplinar, mas ter-se-ia igualmente de apoiar a participação de 
grupos de investigação Portugueses em programas comunitários, onde estes assuntos são investigados há mais tempo. Finalmente, é de salientar que a constante monitorização da variabilidade climática de todo o território Português (incluindo os arquipélagos autónomos), com vista a uma detecção atempada de todo o tipo de alterações climáticas, deveria corresponder a um objectivo de interesse nacional. Infelizmente tal nível de consciencialização não parece ser reconhecido pelas autoridades responsáveis (talvez devido à prioridade dada a outras áreas), permanecendo a principal instituição vocacionada para o efeito (Departamento de Clima do Instituto Meteorológico, IM) sem os recursos humanos e financeiros para a realizar. No entanto, nota-se algum avanço nesta área, com a recente criação de uma Comissão Interministrial para as Alterações Climáticas, incumbida de elaborar a estratégia nacional para as AC, entre outras tarefas.

Observando a importância que se tem vindo a dar às alterações climáticas, nos últimos trinta anos, o presente texto destina-se a revelar alguns dos últimos desenvolvimentos no campo científico deste complexo problema ambiental. A ciência das alterações climáticas tem vindo a desenvolver-se muito rapidamente nos últimos anos. Pretende-se, aqui, fornecer uma visão global dos assuntos mais polémicos, numa altura em que cientistas de todo o planeta estão a trabalhar criativamente em conjunto para produzirem o Terceiro Relatório do Painel Intergovernamental das Alterações Climáticas. Na primeira secção, serão focados alguns aspectos históricos incluindo as observações mais recentes do clima, à escala planetária e nacional. As actividades e objectivos do Painel Intergovernamental acima referido são relembradas. Segue-se uma secção dedicada exclusivamente à análise dos novos cenários de emissões de gases com efeito de estufa, que foram recentemente (1999) apresentados à comunidade científica internacional. Estes cenários são a base de todo um pro-cesso que permite avaliar os impactos das AC no futuro e formular medidas para a sua mitigação. Faz-se também uma súmula dos avanços mais significativos em termos de impactos das AC nas diferentes actividades socioeconómicas.

\section{A CIÊNCIA DAS ALTERAÇÕES CLIMÁTICAS}

\section{Aspectos históricos}

Embora se possa pensar que as alterações climáticas correspondem a um conceito científico relativamente recente, tal não é verdade. De facto, já em 1827, Fourier terá sugerido um primeiro modelo conceptual para o fenómeno que actualmente conhecemos como constituindo o efeito de estufa (RAMANTHAN, 1998; RodHe et al., 1998). Também no século passado se iniciou a procura de relações entre os ciclos de manchas solares e o clima da Terra, sendo de salientar que até à presente data estes estudos são, em grande medida, inconclusivos (Borroughs, 1992, Mann et al., 1999). Seria apenas em 1896 que 
Arrhenius (futuro prémio Nobel da química) soube fundamentar a influência dos GEE na temperatura da atmosfera terrestre. Por outro lado, Arrhenius anteviu a importância da influência humana na alteração da temperatura global do planeta (RodHe et al., 1998). No entanto, é de salientar que, durante o século XX, a própria comunidade científica raramente atribuiu grande importância ao problema das AC. Este cepticismo do meio científico modificouse significativamente nos últimos 30 anos, em grande medida devido aos seguintes factores (SCHNEIDER, 1989):

- A obtenção de séries longas de dados climatológicos para diferentes regiões do globo, o que permitiu observar importantes alterações à escala planetária e não somente numa dada região.

- O desenvolvimento de computadores suficientemente potentes, bem como de Modelos de Circulação Global (Global Circulation Models GCMs) ${ }^{3}$ capazes de simular grande parte dos processos físicos, químicos e biológicos que afectam todo o sistema climático.

- A constatação de que, apesar do conforto proporcionado pela tecnologia moderna, a humanidade é bastante vulnerável, mesmo face a pequenas alterações do clima.

- A consciencialização de que o ambiente (incluindo o clima) do nosso planeta tem sido sujeito a uma agressão crescente por parte do homem, desde o início da revolução industrial.

\section{Observações recentes do Sistema Climático}

Actualmente sabemos que a temperatura média da superfície da Terra sofreu um acréscimo de cerca de $0.6^{\circ} \mathrm{C}$ desde o início deste século. Este acréscimo resultou de um aumento das temperaturas mínimas diárias, superior ao correspondente aumento das temperaturas máximas, diminuindo desta forma a amplitude térmica diária da temperatura. Por outro lado, a extensão das calotes polares e dos glaciares sofreu uma diminuição, a qual foi acompanhada de um aumento do nível médio dos oceanos da ordem dos 10 a $25 \mathrm{~cm}$ (IPCC, 1996). Nas últimas três décadas, tem-se vindo a assistir a um aumento contínuo da temperatura média do globo (Fig. 1), com a agravante de os 4 anos mais quentes de que há registo terem sido observados todos na última década, respectivamente 1990, 1995, 1997 e 1998.

\footnotetext{
3 Modelos computacionais que tentam simular o clima da Terra, integrando no tempo um vasto conjunto de equações diferenciais que incorporam, na medida do possível, os processos físicos, quimicos e biológicos que caracterizam o sistema atmosfera-oceano.
} 


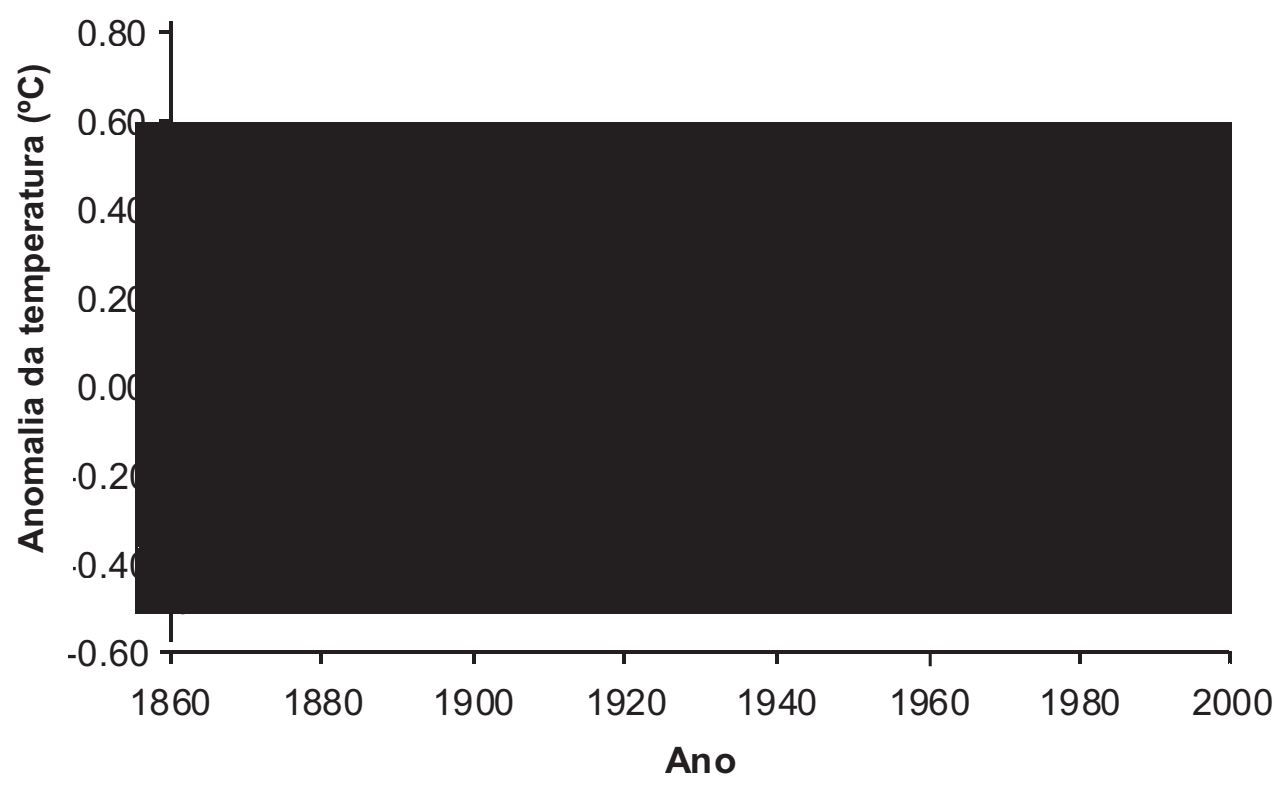

FIG. 1 - Anomalias da temperatura média anual à superfície, relativamente à média de 1961-90. A curva representa uma média móvel de 10 anos (Adaptado do Hadley Centre, 1998).

Publicada com a autorização do HADLEY CENTRE

FIG. 1 - Annual mean surface temperature anomaly pattern from 1961 to 1990. Curved line represents a 10-year mobile mean (adapted from Hadley Centre, 1998).

No ano de 1998, registou-se a temperatura média global mais elevada desde 1860 (Met. OfFICE, 1998). Esta sequência de meses extraordinariamente quentes no biénio 1997/98 deveu-se, em grande medida, ao aparecimento de um forte episódio do El Niño. De facto, devido a uma singular coincidência, a Conferência de Quioto teve lugar em Dezembro de 1997, durante a fase madura (temperaturas mais elevadas na superfície do mar) de um dos episódios mais intensos de El Niño de que há memória.

É de salientar que ainda não há uma garantia de uma associação entre o aumento de frequência e amplitude de El Niños e as AC. Contudo, resultados preliminares com Modelos de Circulação Global já confirmaram um previsível aumento na frequência e intensidade dos episódios de El Niño num planeta mais quente (TIMMERMAN et al., 1999). Outra estranha coincidência foi o facto de a última Conferência das Partes (em Buenos Aires) ter decorrido ao mesmo tempo que o furacão Mitch desvastava grandes áreas da América Central. Talvez estas coincidências estejam a tornar-se cada vez mais frequentes devido às AC; no entanto, o estado actual do conhecimento científico não permite confirmar tal afirmação. Por outro lado, estudos recentes (WIGLEY et al., 1998) voltam a 
confirmar que a intervenção humana e o forcing solar são factores responsáveis pelas alterações do clima global do nosso planeta.

\section{Observações recentes do Clima de Portugal}

Tal como na maior parte das regiões do globo, a temperatura média em Portugal continental registou um acréscimo significativo (superior a $0.5^{\circ} \mathrm{C}$ ) nos últimos 100 anos. Este aumento foi superior nas estações do Inverno e Primavera (SchöNwwIESE et al., 1993). Por contraste, a precipitação média anual registada sobre o território continental de Portugal não sofreu alterações estatisticamente significativas durante o século XX (Mendes e Coelho, 1993). No entanto, a distribuição sazonal da precipitação ao longo do ano hidrológico (definido de Outubro a Setembro do ano seguinte, cobrindo a estação chuvosa) sofreu importantes alterações. Vários estudos recentes permitiram constatar que a precipitação para o mês de Março tem vindo a sofrer uma redução acentuada desde os anos 60 (Fig. 2), acompanhada por um acentuado acréscimo no mês de Fevereiro (Zhang et al., 1997; Trigo e DaCamara, 2000).

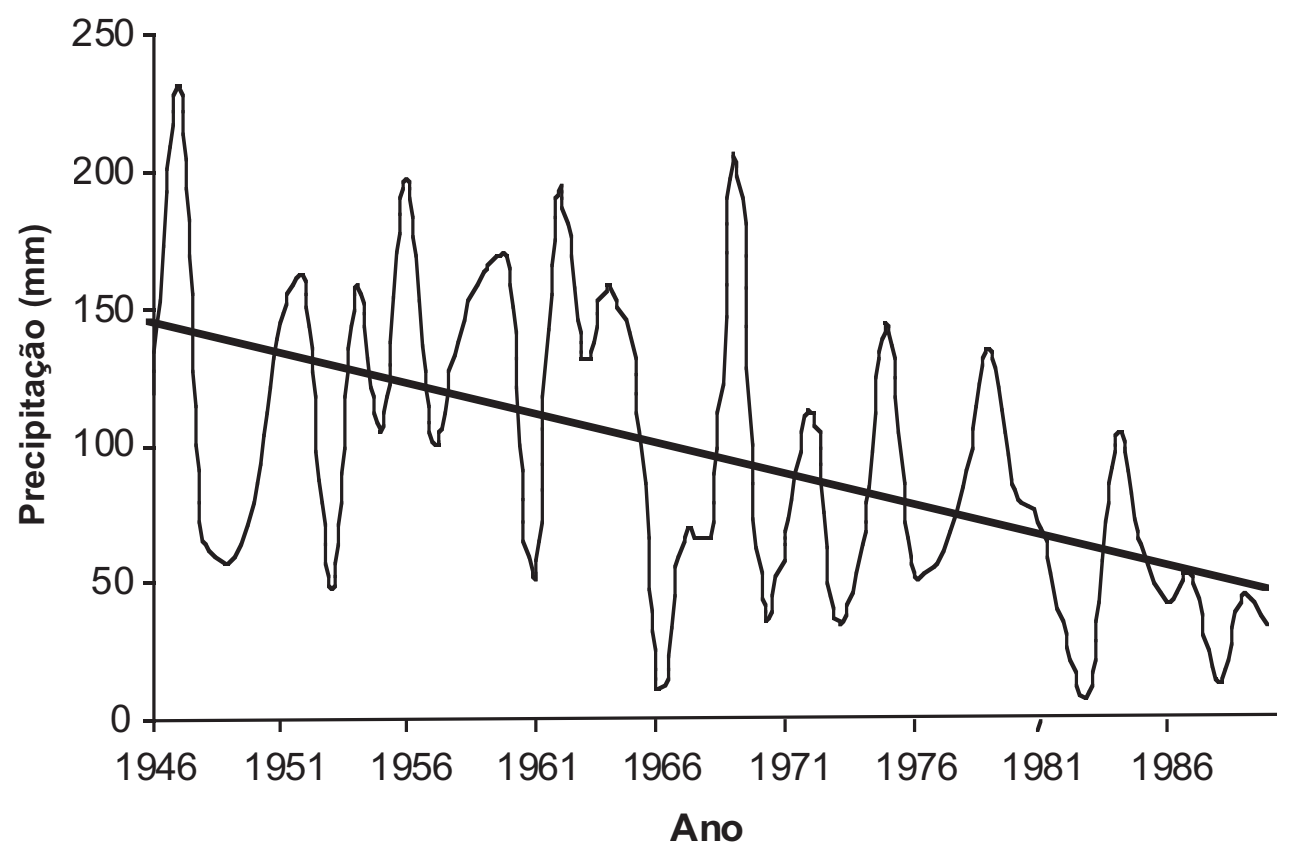

FIG. 2 - Precipitação média do mês de Março em Portugal entre 1946 e 1990 (usando 18 estações) com o respectivo declive (Trigo E DaCAmara, 2000).

FIG. 2 - Average mean precipitation for March in Portugal between 1946 and 1990 (using 18 stations) with respective decline (TRIGO and DACAMARA, 2000). 
Esta mudança no regime da precipitação corresponde à alteração da circulação atmosférica predominante, tendo-se verificado que as situações sinópticas responsáveis pela maior parte da precipitação registada em Portugal (depressões e respectivas superfícies frontais) sofreram uma diminuição acentuada durante o mês de Março (Mendes e Coelho, 1993; Trigo e DaCamara, 2000). Este fenómeno em concreto é de grande relevância para uma correcta gestão de importantes actividades económicas, como é o caso da agricultura ou da produção de energia hidroeléctrica, para citar apenas algumas.

\section{PAINEL INTERGOVERNAMENTAL DAS ALTERAÇÕES CLIMÁTICAS (IPCC)}

Em 1988, a Organização Meteorológica Mundial e o Programa das Nações Unidas para o Ambiente (PNUA) estabeleceram o IPCC (Inter-governmental Panel on Climate Change - Painel Intergovernamental das Alterações Climáticas) para avaliar a informação científica acerca das AC, os impactos ambientais e socioeconómicos das AC e formular estratégias para a sua mitigação. Dividido em três grupos de trabalho: ciência, impactos e aspectos socioeconómicos, o IPCC tem vindo a produzir regularmente relatórios revendo toda a literatura relevante sobre o assunto. O primeiro relatório foi publicado em 1990, o segundo em 1995, e o terceiro foi publicado no Verão de 2001. Foi o primeiro relatório que serviu de base para as negociações da Convenção-Quadro das Nações Unidas sobre as Alterações Climáticas. Mas foi apenas no segundo relatório que o IPCC concluiu, após acesa discussão, que o aumento dos GEE desde a revolução industrial provocam alterações no clima, sendo aquelas os principais responsáveis pelo aumento recente da temperatura à superfície da Terra. No entanto, há ainda um grande leque de incertezas em torno de alguns aspectos da ciência das AC. Citem-se, entre outras, as incertezas relativas às futuras emissões de GEE e aerossóis, assim como ao respectivo ciclo; à representação de processos climáticos em modelos numéricos, espe-cialmente retroacções relacionadas com nuvens, neve, vegetação e processos que decorrem nos oceanos, entre outros; e, por último, à qualidade dos dados instrumentais das variáveis climáticas.

\section{Cenários}

Todo o processo de obtenção de futuras mudanças da temperatura global terrestre (e outras variáveis climáticas) inicia-se com a construção de cenários ${ }^{4}$,

\footnotetext{
4 A palavra «cenários» será utilizada para projecção de emissões de GEE e «previsões» para resultados dos modelos. Na literatura científica é corrente a utilização de «emission scenarios» e «climate change scenarios» respectivamente.
} 
deste facto advém a sua importância. Um cenário pode ser definido como uma simples descrição da forma como a influência humana na Terra se irá desenrolar no futuro, baseando-se num conjunto de suposições base, acerca de relações-chave e mecanismos geradores (grau de mudanças tecnológicas, flutuações monetárias, etc.), que devem ser coerentes e consistentes. Nota-se portanto que, na construção de cenários, se inicia uma cascata de incertezas que vai aumentando de amplitude até ao resultado final.

Em 1992, o IPCC publicou seis cenários (LEGGETT et al., 1992) relativos às futuras emissões dos principais gases de efeito de estufa $\left(\mathrm{CO}_{2}, \mathrm{CO}, \mathrm{CH}_{4}\right.$, $\mathrm{N}_{2} \mathrm{O}, \mathrm{NO}_{\mathrm{x}}$ e $\mathrm{SO}_{2}$ ) para o período compreendido entre 1990 e 2100 . Estes foram posteriormente utilizados por climatologistas e outros cientistas da atmosfera para produzir previsões sobre o clima futuro, actualizando o trabalho efectuado durante o primeiro relatório do IPCC (de 1990). Estes cenários ficaram amplamente conhecidos na literatura como IS92 (variantes: a, b, c, d, e, f).

$\mathrm{Na}$ altura da sua publicação, os IS92 foram considerados o estado da arte em termos de cenários. Naturalmente, após seis anos, muito se alterou, tendo sido reconhecido, entre outros, o importante efeito das emissões de sulfatos assim como a adopção de medidas regionais de políticas de controlo de GEE. O reedificar dos estados da Europa de Leste e da antiga União Soviética tiveram efeitos consideráveis na actividade económica e nas emissões, que não tinham sido incluídos nos cenários IS92. Por outro lado, estes cenários não eram representativos de algumas regiões do planeta (principalmente em relação aos países em desenvolvimento). Recentemente, os modelos de avaliação integrada tornaram possível a criação de cenários que consideram as interacções entre a utilização de recursos energéticos, a economia e as mudanças de utilização do solo.

Tendo em conta esta nova realidade, decidiu criar-se um novo conjunto de cenários para que estes pudessem ter uma aplicação mais alargada que os seus predecessores. Assim, no novo relatório sobre cenários (SRES, Special Report on Emission Scenarios) foi adoptada uma abordagem mais integrada, passando os cenários a ser desenvolvidos através de um esforço colectivo de peritos em todas as áreas relevantes. O processo envolveu três fases, incluindo a primeira fase a revisão de suposições-chave para os modeladores. Estas suposições integraram projecções populacionais, mudanças tecnológicas entre outras. Durante a segunda fase, os modeladores construíram cenários de emissões a partir das suposições fornecidas. Finalmente as saídas dos modelos seriam utilizados para desenvolver novos cenários de emissão sob a forma de resultados médios para os modelos participantes ou resultados de um modelo representativo, dado terem sido analisados mais de 400 cenários diferentes. A gama de cenários resultantes reflectem a incerteza subjacente à sua construção. O desenvolvimento destes foi um "processo aberto", não havendo modelos oficiais ou grupo de peritos. Qualquer investigador poderia ter participado neste processo até Dezembro de 1998.

A equipa que desenvolveu estes cenários decidiu descrevê-los através de pequenas narrativas de maneira a poder facilitar a sua interpretação. O Qua- 
dro I resume as principais características associadas a cada cenário preliminar (o IPCC já aceitou estes cenários como definitivos).

QUADRO I - Parâmetros mais importantes do historial dos diferentes cenários. (Adaptado de SRES, 1998)

TABLE I-Description of the most important parameters used to characterise each scenario (Adapted from SRES, 1998)

\begin{tabular}{|l|l|l|l|l|}
\hline & \multicolumn{1}{|c|}{ A1 } & \multicolumn{1}{c|}{ A2 } & \multicolumn{1}{c|}{ B1 } & \multicolumn{1}{c|}{ B2 } \\
\hline $\begin{array}{l}\text { Crescimento } \\
\text { populacional }\end{array}$ & Moderado & Elevado & Moderado & Moderado \\
\hline $\begin{array}{l}\text { Desenvolvimento } \\
\text { económico }\end{array}$ & Rápido & Lento & Rápido & Moderado \\
\hline $\begin{array}{l}\text { Desenvolvimento } \\
\text { tecnológico }\end{array}$ & Rápido & Lento & Rápido & Moderado \\
\hline Investimento & Elevado & Baixo & Elevado & Médio \\
\hline $\begin{array}{l}\text { Desenvolvimento cul- } \\
\text { cultural (através de) }\end{array}$ & Educação & $\begin{array}{l}\text { Valores } \\
\text { familiares }\end{array}$ & $\begin{array}{l}\text { Consciência } \\
\text { ambiental } \\
\text { e social }\end{array}$ & Educação \\
\hline $\begin{array}{l}\text { Institucionalização } \\
\text { Nacional } \\
\text { e internacional }\end{array}$ & Local e regional & $\begin{array}{l}\text { Local, nacional } \\
\text { e internacional }\end{array}$ & Local \\
\hline Preocupação ambiental & Média & Baixa & Elevado & Elevada \\
\hline
\end{tabular}

São notórias algumas semelhanças entre os cenários A1 e B1. Pequenas diferenças residem no facto de, neste último, serem investidos grande parte dos ganhos para melhorar a eficiência do uso de recursos naturais, equidade, instituições sociais, e protecção ambiental. Depreende-se também que A2 é provavelmente o cenário mais pessimista, o que não o torna menos importante que os restantes. Algumas destas diferenças e semelhanças podem ser melhor observadas nas figuras 3 e 4, que representam respectivamente, as emissões globais de dióxido de carbono $\left(\mathrm{CO}_{2}\right)$ e de metano $\left(\mathrm{CH}_{4}\right)$ para cada um dos cenários.

O grupo que desenvolveu estes cenários decidiu não indicar um «cenário mais provável» pois o futuro é intrinsecamente imprevisível e haverá diferentes pontos de vista sobre a selecção do cenário mais plausível. Os cenários cobrem uma grande parte (cerca de $90 \%$ ), mas não a totalidade dos futuros possíveis. «Surpresas», como uma guerra nuclear (que provocaria um decréscimo abrupto da temperatura durante anos) ou descobertas de novas fontes energéticas (livres de GEE) poderão vir a ocorrer.

Estes cenários preliminares já começam a ser utilizados pela comunidade científica. Usando um modelo climático simples (consistente com o Segundo Relatório do IPCC), ideal para explorar as consequências de diferentes cenários, pode-se prever uma gama de possíveis incrementos da temperatura global terrestre durante os próximos cem anos (Fig. 5). 


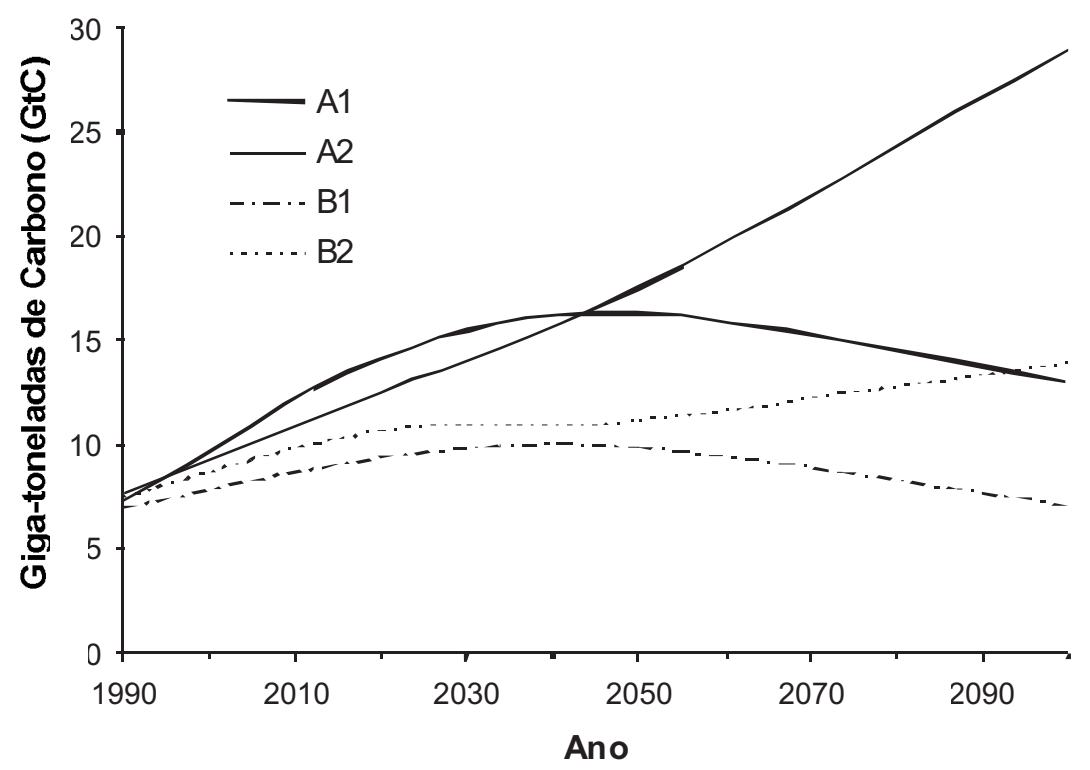

FIG. 3 - Cenários de futuras emissões globais de dióxido de carbono (Adaptado de SRES, 1998)

FIG. 3 -Scenarios of future global emissions of carbon dioxide (adapted from SRES, 1998)

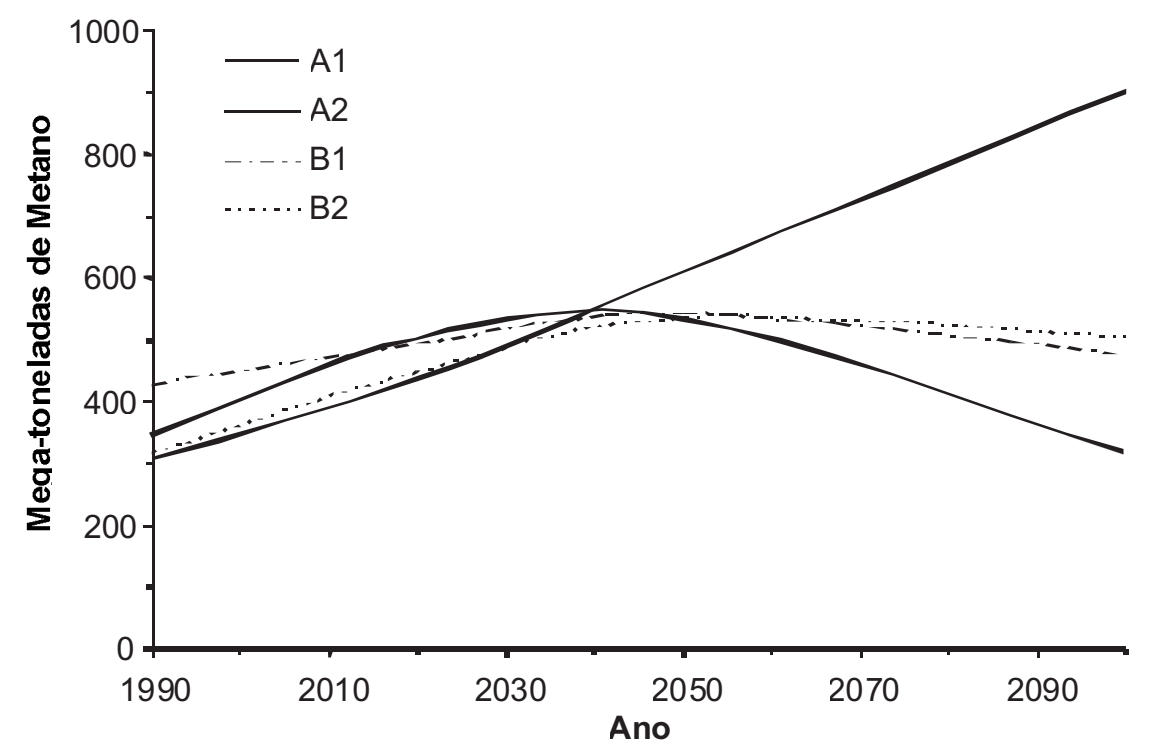

FIG. 4 - Cenários de futuras emissões globais de metano. (Adaptado de SRES, 1998). FIG. 4 -Scenarios of future global emissions of methane (adapted from SRES, 1998). 


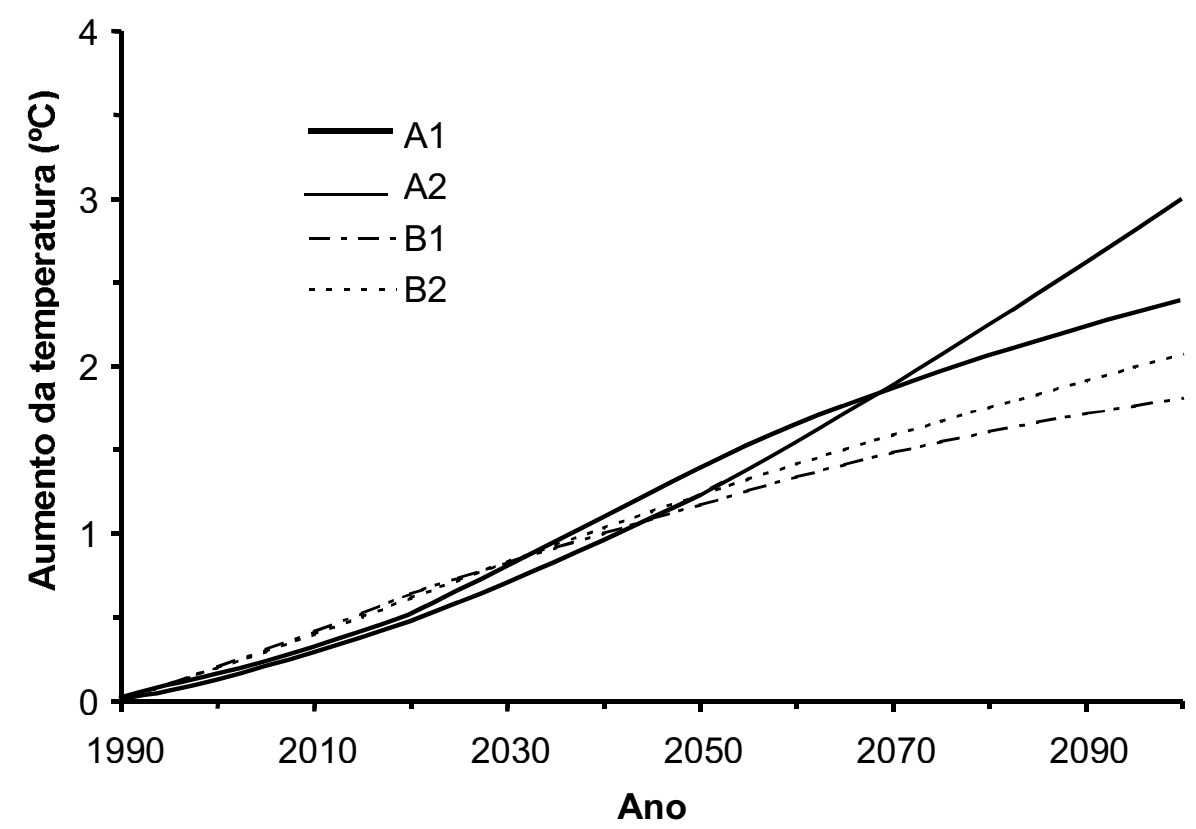

FIG. 5 - Previsão do aumento da temperatura global terrestre, para os 4 cenários a partir de 1990, projectado por um modelo climático simples (DESSAI E Hulme, 2001).

FIG. 5 -Estimated increase of global terrestrial temperature for the four scenarios as from 1990 projected for a simple climatic model (DESSAI and HulME, 2001)

Nota-se de imediato que os diferentes aumentos da temperatura estão intimamente relacionados com os diferentes cenários ${ }^{5}$. Contudo, até ao ano de 2050, parece ser difícil interpretar em qual das trajectórias nos encontramos. A figura 5 utiliza o valor de $2.5^{\circ} \mathrm{C}$ para a sensitividade do clima ${ }^{6}$, mas se se utilizar um intervalo de $1.5^{\circ} \mathrm{C}$ a $4.5^{\circ} \mathrm{C}$ (sugerido pelo IPCC) o aumento da temperatura global até 2100 poderá variar entre $1.2^{\circ} \mathrm{C}$ para o cenário $\mathrm{B} 1$ e $4.2^{\circ} \mathrm{C}$ para o cenário A2.

É possível analisar este problema das alterações climáticas de uma forma mais realística utilizando uma abordagem probabilística do tipo Bayseano (Fig. 6).

5 Este modelo apenas considera forcings antropogénicos (GEE e dióxido de enxofre), ignorando a variabilidade natural do clima, assim como o forcing solar.

6 A sensitividade do clima é a resposta do sistema climático (em termos de variação da temperatura do globo) à duplicação da concentração de $\mathrm{CO}_{2}$ atmosferico. 


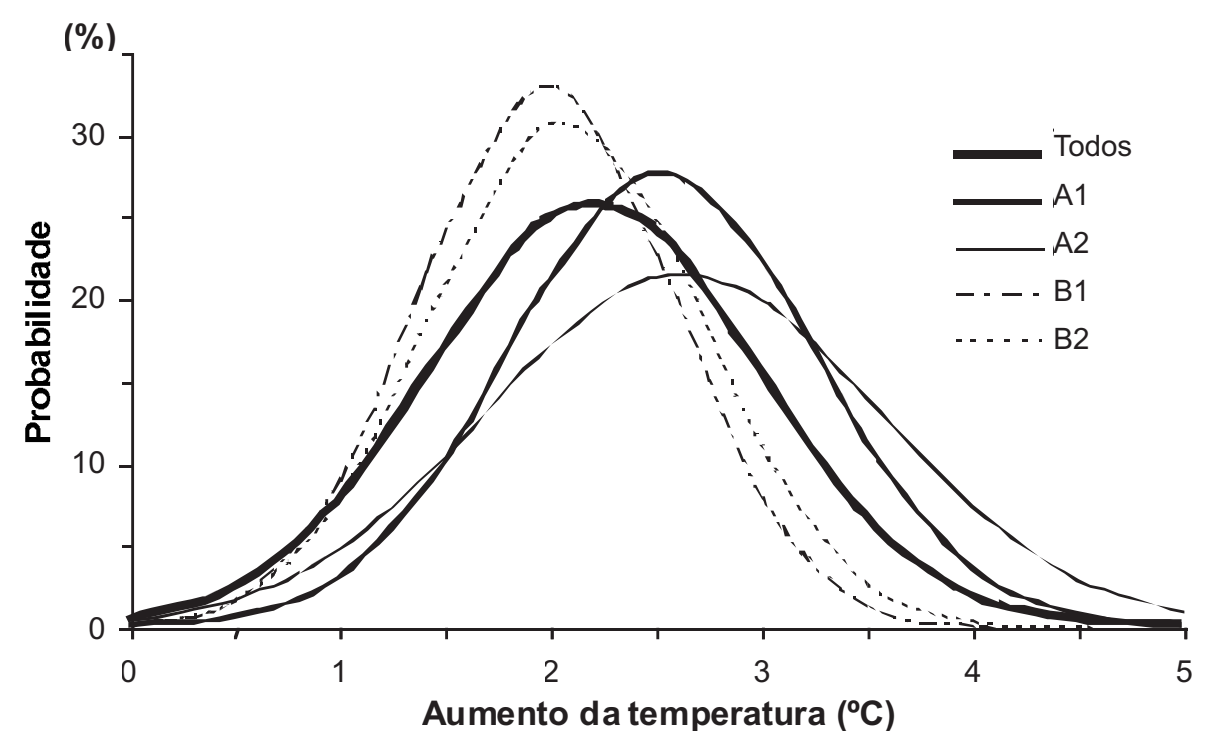

FIG. 6 - Distribuição Bayesiana dos diferentes cenários para mudanças na temperatura média global em 2100 (inclui variabilidade natural do clima) (Dessai e Hulme, 2001).

FIG. 6-Bayesian distribution of the different scenarios for changes in global mean temperature in 2100 (including natural variability) (Dessai and Hulme, 2001).

Esta abordagem é baseada no uso intensivo de simulações Monte Carlo ${ }^{7}$, onde vários parâmetros (como a sensitividade do clima, o ciclo do carbono e os cenários de emissões) têm uma determinada distribuição de probabilidade. A Figura 6 sumariza os cenários descritos anteriormente (que não assumem qualquer tipo de intervenção política para a redução dos GEE) e vários sub-cenários que assumem a implementação do Protocolo de Quioto, que pretende reduzir em 5\% (relativamente a 1990), um conjunto de 6 GEE, de 2008 a 2012 por parte dos países industrializados. Estes sub-cenários, que também consideram diferentes trajectórias pós-Quioto, estão incluídos nesta simulação, mas não foram explicitamente apresentados na figura. A figura 6 mostra que o aumento da temperatura vai estar muito dependente do cenário que se vier a verificar, sendo o cenário A2 o mais temível e B1 o de menor mudança. Este tipo de análise é particularmente útil para quantificar o grau de incerteza associado a cada cenário e permitir que estudos de impactos sejam expressos em termos de risco.

7 Simulações aleatórias que correm milhares de vezes, variando os parâmetros com uma probabilidade pre-definida (neste caso tiradas de uma distribuição normal). 


\section{Impactos}

Em 1998, o IPCC publicou um relatório especial denominado «Impactos regionais das alterações climáticas: uma avaliação de vulnerabilidade» (WATSON et al., 1998). Este documento mostra de uma forma inequívoca que as AC poderão afectar a localização geográfica de ecossistemas, a interacção de espécies e os benefícios que deles (ecossistemas) advêm. Também recentemente foi publicado um relatório pelo Instituto Meteorológico Britânico (Met. OfFice, 1998), contendo os possíveis cenários de alterações climáticas para o próximo século, obtidos com a última geração de Modelos de Circulação Global. Nesta secção, gostaríamos de salientar alguns dos principais impactos das AC contidos nos dois relatórios referidos, sublinhando, por um lado, o seu carácter regional e, por outro, o facto de serem relativos a diferentes sectores de actividades socioeconómicas.

- O ciclo hidrológico e a disponibilidade de água serão severamente afectados, especialmente em regiões áridas e semi-áridas do planeta. Assim, prevê-se que um dos principais impactos negativos das AC na sociedade humana venha a ser no sector dos recursos hídricos. Actualmente, cerca de $1 / 3$ da população mundial vive em regióes com problemas de acesso a água. Prevê-se que, em 2025, cerca de 2/3 de uma população bastante superior à actual tenha problemas na obtenção de água. É de salientar que tal facto ficar-se-á a dever essencialmente ao aumento de população, contribuindo as $\mathrm{AC}$ «apenas» para exacerbar o problema.

- As AC irão afectar de forma positiva a produção agrícola nas latitudes mais elevadas, como o Canadá ou o norte da Europa, mas terão um impacto bastante negativo nas latitudes mais baixas, incluindo praticamente todo o continente Africano, bem como grande parte da América do Sul. Em particular, prevê-se uma enorme redução na área da floresta tropical amazónica.

- Zonas costeiras, onde grande parte da população mundial habita, serão confrontadas com o aumento do nível dos mares. As previsões apontam para que, em 2050, o nível médio dos oceanos suba mais cerca de $20 \mathrm{~cm}$. Se a construção/manutenção de protecções costeiras evoluir como até à presente data, então é de temer que um número extra de 20 milhões de pessoas/ano fiquem susceptíveis de sofrer inundações frequentes. As regiões mais vulneráveis encontram-se no sudeste asiático (especialmente no Bangladesh), bem como pequenos estados/ilhas nos oceanos Índico e Pacífico. No entanto é de realçar que muitas regiões com maiores capacidades de adaptação, como a Holanda, a laguna de Veneza ou o delta do Mississipi estarão igualmente sujeitas a um risco acrescido. 
- A saúde humana também será afectada, esperando-se um aumento de doenças tropicais infecto-contagiosas. Em especial prevê-se um aumento do risco de se contrair a malária em zonas do globo onde actualmente a doença não é endémica.

- Esperam-se alterações na frequência de eventos extremos de precipitação, causando mais situações de seca em algumas regiões do globo, mas também inundações mais frequentes noutras. Um estudo encomendado pelo Ministério do Ambiente do Reino Unido (Hulme et al., 1998) prevê que as ilhas britânicas serão atingidos com maior frequência por depressões intensas no Inverno, mas a zona sul será afectada por períodos de seca, tal como aconteceu no Verão de 1995 (Palutikof et al., 1997), enquanto a região norte passará a estar sobre a influência de um regime mais pluvioso. Embora não haja a certeza de que o número de furacões que atingem a América do norte esteja a aumentar, existe um alargado consentimento de que os seus efeitos são cada vez mais devastadores (o furacão Andrew que atingiu a Flórida em 1992 constituiu um recorde absoluto em termos de estragos nos EUA; por outro lado, o furacão Mitch, que devastou as Honduras e Nicarágua, em Novembro de 1998, foi responsável pela morte de mais de 10.000 pessoas)

- Em Portugal, existem relativamente poucos estudos sobre possíveis impactos das alterações climáticas. Na realidade são ainda insuficientes os estudos sobre a própria variabilidade climática bem como a sua forte interdependência com a circulação atmosférica. Os principais trabalhos de investigação existentes tem sido efectuados essencialmente nas universidades. Neste âmbito, é de salientar o papel do grupo de meteorologia da Faculdade de Ciências da Universidade de Lisboa, liderado pelo Prof. João Corte-Real que tem vindo a participar ao longo dos anos 90 em vários projectos Europeus (ECLAT, MEDALUS, WRINCLE) e nacionais de grande envergadura, com os principais resultados publicados em revistas internacionais de reconhecido valor (CORTE-REAL et al., 1995, Zhang et al., 1997, Corte-Real et al., 1998; Corte-Real et al., 1999a; CoRTE-Real et al., 1999b). Um dos autores aplicou recentemente a técnica de redes neuronais para obter previsões de temperaturas maxímas e minímas para Portugal (Trigo e Palutikof, 1999).

\section{AGRADECIMENTOS}

Gostaríamos de agradecer ao Instituto Meteorológico Britânico (Met. Office) pelo acesso a algumas das figuras e à Dra. Isabel Trigo pelas várias sugestões sobre versões anteriores deste artigo. 


\section{BIBLIOGRAFIA}

Borroughs,W.J. (1992) - Weather Cycles: Real or Imaginary? Cambridge University Press, Cambridge.

Corte-ReAl, J.; X. Zhang; X. WANG (1995) - Downscaling GCM information to regional scales: a non-parametric multivariate approach. Climate Dynamics, 11: 413-424.

Corte-Real, J.; B. QIAN; H. Xu (1998) - Regional climate change in Portugal: precipitation variability associated with large-scale atmospheric circulation. International Journal of Climatology, 18: 619-635.

Corte-Real, J.; B. Qian; H. Xu (1999a) - Circulation Patterns, Daily Precipitation in Portugal and Implications for Climate Change Simulated by the Second Hadley Centre GCM. Climate Research, 13: 61-75.

CoRte-Real, J.; H. Xu; B. Qian (1999b) - A weather generator for obtaining daily precipitation scenarios based on circulation patterns. Climate Dynamics, 15: 921-925.

Dessai, S., M. Hulme (2001) - Climatic implications of revised IPCC emission scenarios, the Kyoto Protocol and quantification of uncertainties. (Aceite para publicação na revista Integrated Assessment).

IPCC (1996) Climate Change 1995: The Science of Climate Change. Cambridge University Press, Cambridge.

Hulme, M.; G. J. JENKIns (1998) - Climate change scenarios for the UK: scientific report. UKCIP Technical Report No.1, Climatic Research Unit, Norwich,

Leggett, J.; W. J. Pepper; R. J. Swart; J. Edmonds; L. G. Meira Filho; I. Mintzer; M. X. Wang; J. Watson (1992) - Emissions Scenarios for the IPCC: An Update. in Climate Change 1992: The Supplementary Report to the IPCC Scientific Assessment, Cambridge University Press, Cambridge.

Mann, M. E.; R. S. Bradley; M. K. Hughes (1999) - Northern hemisphere temperatures during the past millennium: influences, uncertainties, and limitations. Geophysical Research Letters, 26: 759-762.

Mendes, J. C.; M. F. S. Coelho (1993) - Variabilidade climática em Portugal continental: quantidade de precipitação. Monografia de Meteorologia e Geofísica nº43, INMG, Lisboa.

MET. OfFICE (1998) - Climate change and its impacts: some highlights from the ongoing UK research programme: a first look at results from the Hadley Centre's new climate model. Crown, Bracknell.

Parry, M.; N. Arnell; M. Hulme; R. Nicholls; M. Livermore (1998) - Adapting to the inevitable. Nature, 395: 741.

Palutikof, J. P.; S. Subak; M. D. Agnew (1997)-Economic impacts of the hot summer and unusually warm year of 1995. University of East Anglia, Norwich.

Peixoto, J. P. (1987) - As variações do clima e do ambiente. Secretaria de Estado do Ambiente e dos Recursos Naturais, Lisboa.

Pielke, Jr., R. A. (1998)-Rethinking the role of adaptation in climate policy. Global Environmental Change, 8:159-170.

Ramanathan, V. (1998) - Trace-gas greenhouse effect and global warming. Ambio, 27(3): 187-197. 
Rodhe, H.; R. Charlson; E. Crawford (1998) - Svante Arrhenius and the greenhouse effect. Ambio, 26(1): 3-5.

SchneIDER, S. H. (1989) - Global warming. Are we entering the Greenhouse Century? Sierra Club Books, San Fransisco.

Schönwiese, C.-D.; J. RapP; T. Fuchs; M. Denhard (1993)-Klimatrend-Atlas Europe 18911990. Berichte des Zentrums für Umweltforschung, No. 20. ZUF-Verlag, Frankfurt.

Special Report on Emissions Scenarios (SRES, 1998) OPEN PROCESS. Intergovernmental Panel on Climate Change-Working Group III: Mitigation of Climate Change http://sres.ciesin.org/

Timmerman, A.; J. Oberhuber; A. Bacher; M. Esch; M. Latif; E. Roeckner (1999) - Increased El Niño frequency in a climate model forced by future greenhouse warming. Nature, 398: 694-696.

Trigo, R. M.; J. P. Palutikof (1999) - Simulation of daily temperatures for climate change scenarios over Portugal: A Neural Network Model approach. Climate Research, 13: 45-59.

Trigo, R. M.; C. DaCAmara (2000) - Circulation Weather Types and their impact on the precipitation regime in Portugal. International Journal of Climatology , 20: 1559-1581.

Watson, R. T.; M. C. ZinYowera; R.H. Moss (1998) - The Regional Impacts of Climate Change: An Assessment of Vulnerability. Cambridge University Press, Cambridge.

Wigley, T. M. L.; R. L. Smith; B. D. SAnTer (1998) - Anthropogenic influence on the autocorrelation structure of hemispheric-mean temperatures. Science, 282(5394): 2285-2288.

ZhanG, X.; X. L. WANG; J. CoRTe-Real (1997) - On the relationships between daily circulation patterns and precipitation in Portugal. J. Geophys. Res., (102): 13495-13507. 